\title{
THE ACTION OF PHTHALIC ANHYDRIDE ON RESACETOPHENONE.
}

\author{
BY HENRY A TORREY ANS C. M. BREWSTER.
}

Received March is 1909 .

In the preceding paper by $\mathrm{H}$. B. Kipper and one of us we have called attention to the replacement of the acetyl group by the nitrobenzoyl group in resorcinol diacetate and hydroquinonol diacetate. In the present article we wish to record a more remarkable reaction in which the acetyl group

in resacetophenone, $\mathrm{HO}$

$\mathrm{OH}$

radical is directly attached to the ring, has been replaced by a group of higher molecular weight. By heating two molecules of resacetophenone and one molecule of phthalic anhydride with a dehydrating agent, such as anhydrous zinc chloride, sulphuric acid, or phosphoric acid, then acetic acid is given off and fluorescein is formed in large amount. It has been known for a long time that acetophenone, heated with concentrated sulphuric acid, gives benzoic acid and benzenesulphonic acid ${ }^{1}$ and Hoogewerf and van Dorp ${ }^{2}$ have shown that in substituted aromatic methyl ketones carrying a methyl group in the ortho position to the acetyl group, sulphuric acid has the power of replacing the ketone radical by hydrogen. while Klages ${ }^{3}$ had found somewhat earlier that although the aromatic

ketones of the type

Y-COR were unaffected by heating with phos-

phoric acid, those ketones in which an alkyl group is in the ortho position may be changed into the corresponding hydrocarbon; the decomposition takes place most easily with diortho alkyl derivatives. The formation of fluoresecin from resacetophenone and phthalic anhydride does not seem to be due to the formation of resorcinol by the splitting out of the acetyl group which then reacts with the phthalic anhydride, for when resacetophenone was heated with concentrated sulphuric acid no odor of acctic acid was noticed.

The procedure in this method for preparing fluorescein was as follows: The mixture of 20 grams of resacetophenone and Io grams of phthalic anhydride, after slightly moistening with water and adding 5 grams of concentrated sulphuric acid, was heated with constant stirring until melted. The rate of condensation was watched by dissolving small portions in sodium hydroxide and observing the color and quality of the precipitate obtained on acidification. When a large vield of a bright

Krekeler, Ber., I9, 678.

-Koninhlijke Akad. van IFetenschappen te Amsterdam, Igor, I73. Chem. Centr., $72[2]$, III 7 .

${ }^{3}$ Ber., 32, I 549 . 
yellow precipitate was secured, the reaction was stopped and the mixture poured into a large quantity of cold water, when the fluorescein separates out in a bright yellow, flocculent mass; if a dark precipitate is obtained, the mixture has been heated too long. The fluorescein may then be purified by fractional precipitation from an alkaline solution with acid, which gradually removes a tarry impurity probably containing resaceteïn. Another method of purification consists in dissolving the crude fluorescein in concentrated sulphuric acid diluted with an equal volume of water and precipitating after filtration by neutralization with sodium hydroxide. That acetic acid is actually given off in the reaction was shown by the odor, by the ferric chloride and the ethyl acetate tests. That the compound formed was actually fluorescein was shown by conversion into the diacetate, the dichloride and eosine. The diacetate made either by heating with acetic anhydride or by acetylation with acetyl chloride and pyridine in glacial acetic acid, after purification by crystallization from acetone, melted at $20 \mathrm{I}^{\circ}$, while Baeyer ${ }^{1}$ gives $200^{\circ}$.
Calculated for $\mathrm{C}_{24} \mathrm{H}_{16} \mathrm{O}_{7}$ :
C, $69.23 ; \mathrm{H}, 3.88$.
Found:
C, $69.04,69.24 ; \mathrm{H}, 4.03,4.09$.

From this diacetate fluorescein was obtained by saponification. The dichloride was made by heating with phosphorus pentachloride at $180^{\circ}$. After crystallization from alcohol it gave a melting-point of $249^{\circ}$ (Baeyer, $252^{\circ}$ ). Calculated for $\mathrm{C}_{20} \mathrm{H}_{10} \mathrm{O}_{3} \mathrm{Cl}_{2}: \mathrm{Cl}$, I9.22; Found, I9.2O.

Eosine was made by adding bromine to an alcoholic solution of the fluoresceïn. Calculated for $\mathrm{C}_{20} \mathrm{H}_{8} \mathrm{O}_{5} \mathrm{Br}: \mathrm{Br}, 49 \cdot 36$; Found, 48.76. Succinyl fluorescein was formed with elimination of acetic acid when the condensation was carried on with succinic acid instead of phthalic anhydride.

\section{THE OPTICAL ROTATION OF SPIRITS OF TURPENTINE.}

by Ceas. H. Herty.

Received Februaty 10, 1908.

Among the physical properties of spirits of turpentine, none has proved of more interest than its optical rotation. In most specimens this property is very marked, and as the liquid is colorless and the determination readily made, many data are found on this subject in chemical literature. Slight variations in the rotation of different samples are to be expected, as spirits of turpentine is not a chemical compound but a mixture of substances, chiefly terpenes. From the results of numerous observations upon commercial samples, the view commonly held previous to I 89 I was that French spirits of turpentine, distilled from the oleoresin of Pinus maritima, is levo-rotatory and that American spirits of turpen-

1 Ann., 183, 1. 